\title{
Effectiveness of Leadership, Management, and Governance Competencies for Performance Improvements at Primary Health Care Entities in Ethiopia: A Before and After Study
}

\author{
Mesele Damte Argaw ${ }^{1^{*}} \mathbb{C}^{\circ}$, Binyam Fekadu Desta $^{1}{ }^{\circledR}$, Sualiha Abdlkader Muktar ${ }^{1}$, \\ Nurhan Tewfik ${ }^{2}$, Bekele Belayihun Tefera ${ }^{3}\left({ }^{\circ}\right.$, Wondwosen Shiferaw Abera ${ }^{1}$ (), \\ Temesgen Ayehu Bele ${ }^{4}\left[{ }^{0}\right.$, Selahadin Seid Buseir ${ }^{2}$, Deirdre Rogers ${ }^{5}$, Kristin Eifler ${ }^{5}$ \\ ${ }^{1}$ USAID Transform: Primary Health Care, JSI Research \& Training Institute, Inc., Addis Ababa, Ethiopia \\ ${ }^{2}$ Federal Ministry of Health, Human Resource Development Directorate Addis Ababa, Ethiopia \\ ${ }^{3}$ USAID Transform: Primary Health Care, Pathfinder International, Addis Ababa, Ethiopia \\ ${ }^{4}$ Federal Ministry of Health, Health Extension and Primary Health Services Directorate, Addis Ababa, Ethiopia \\ ${ }^{5}$ JSI Research \& Training Institute, Inc., Boston, USA \\ Email: *mdamte5@gmail.com, *mesele_damte@et.jsi.com
}

How to cite this paper: Argaw, M. D., Desta, B. F., Muktar, S. A., Tewfik, N., Tefera, B. B., Abera, W. S., Bele, T. A., Buseir, S. S., Rogers, D., \& Eifler, K. (2021). Effectiveness of Leadership, Management, and Governance Competencies for Performance Improvements at Primary Health Care Entities in Ethiopia: A Before and After Study. Journal of Human Resource and Sustainability Studies, 9, 250-275. https://doi.org/10.4236/jhrss.2021.92016

Received: March 3, 2021

Accepted: May 4, 2021

Published: May 7, 2021

Copyright ( 2021 by author(s) and Scientific Research Publishing Inc. This work is licensed under the Creative Commons Attribution International License (CC BY 4.0).

http://creativecommons.org/licenses/by/4.0/

\begin{abstract}
Leadership, management, and governance (LMG) interventions play a significant role in improving management systems, enhancing work climate, and creating responsive health systems. The Ethiopian Federal Ministry of Health with the support of the USAID Transform: Primary Health Care Activity has been cascading basic LMG training and interventions to primary health care staff. The results of this research will help policymakers, program managers, and implementers to make informed decisions in the area of performance improvement. The study used an interventional, a before and after non-experimental survey design to assess the effectiveness of LMG trainings and interventions at primary health care entities. It was conducted from August 28, 2017, to September 30, 2018, in Amhara, Oromia, Tigray, and Southern Nations, Nationalities, and Peoples' regions. Data collection took place through interviewer and self-administered questionnaires across 136 health facilities, in which there were 293 health workers who attended the basic LMG trainings and interventions. In addition, training records were reviewed to capture the changes in knowledge and skills through formal course tests before and after attending the basic LMG training and interventions to ascertain baseline and end-line scores on performance improvement project achievements. Furthermore, 333 non-trained health workers were given the opportunity to rate their organization's leadership, management and gover-
\end{abstract}


nance culture before and after interventions. The data were analyzed using SSPS IBM V 20. The response rates were $100 \%$ for staff who attended the training; and $87 \%$ for staff who did not attend the training and who validated their organization's LMG culture. Of those who attended the training, 235 (80.9\%) scored $70 \%$ or more on post-test exams, and 252 (86\%) scored $80 \%$ or more on their performance improvement project objectives. Using the above-mentioned criteria, composite scores were compiled from written post-test examination score and performance improvement project results. The result showed that 70\% (205/293) of basic LMG trainees successfully completed the basic LMG course. As a result of the LMG trainings, management systems, work climate, and responsiveness of the health system to new challenges were significantly improved $(p<0.001)$. Owing to the leadership projects, within the 136 health facilities, an additional 2290.3 units of health service coverage was gained. Therefore, the basic LMG trainings and interventions were effective in enhancing the knowledge and skills of health workers. It is recommended that providing LMG trainings for more health workers and managers working at primary health care entities will accelerate the implementation of prioritized health sector interventions and is helpful in achieving the Sustainable Development Goals as a global target. An evaluation of the efficiency of the basic LMG training package is also recommended.

\section{Keywords}

Leadership, Management, and Governance, Effectiveness, Performance

Improvement, Training, Organizational Culture, Ethiopia

\section{Background}

According to the World Health Organization (WHO, 2007), a health system is defined as "all organizations, people, and actions whose primary intent is to promote, restore, or maintain health". The WHO health system framework identifies six essential building blocks, or key functions: service delivery; health workforce; information; medical products, vaccines, and technologies; financing; and leadership and governance. To strengthen a health system, in addition to managing the interactions among the six building blocks, each building block needs to be strengthened (WHO, 2007). However, a lack of leadership, governance, and managerial capacity at all levels of health systems was identified as a major constraint to the scale up proven and affordable services in low and middle-income countries (WHO, 2005; Mutale et al., 2017).

Ethiopia's Federal Ministry of Health (FMOH, 2015) defines four pillars of excellence in health, namely: service delivery; quality improvement and assurance; leadership and governance; and, health system capacity to achieve its vision of "healthy, productive and prosperous Ethiopians". Leadership, management, and governance (LMG) interventions thus play a significant role in improving management systems, enhancing the work climate, and creating respon- 
sive systems that are more accessible, with better quality and expanded service availability at affordable costs (MSH, 2005; Chigudu et al., 2014).

United States Agency for International Development (USAID) funds the six-year (2017-2022) Transform: Primary Health Care (PHC) Activity, which is led by Pathfinder International and implemented by a consortium of international and local development partners: (JSI Research \& Training Institute, Inc. [JSI], Abt. Associates Inc., Malaria Consortium, EnCompass, and Ethiopian Midwives Association). During its first year, the project provided technical support in 300 woredas (districts) and has since expanded to 360 woredas in four agrarian regions in Ethiopia, (Amhara, Oromia, Southern Nation Nationalities, and Peoples' [SNNP], and Tigray). The project aims to contribute to the accomplishments of the Government of Ethiopia's Health Sector Transformation Plan and to prevent maternal and child deaths (USAID Transform: Primary Health Care, 2017a).

\subsection{Statement of the Problems}

Ethiopia has adopted and implemented several LMG trainings to strengthen its health system and build services that are accessible to more people by developing inspired leaders, sound management systems, and transparent practices within and among individuals, networks, organizations, and governmental bodies. Some of these training modalities are: leadership for strategic information, a year-long training for policymakers and strategic decision-makers; leadership, management, and governance (Rolle et al., 2011), a set of three different training packages for policymakers and district, health center and hospital managers, implemented through four workshops completed over 6 - 9 months; the primary health care unit management development program (FMOH, 2017), consisting of four workshops over 6 - 12 months per district; and transformational leadership program (Global Health Leadership Institute, 2016), facilitated by the International Institute of Primary Health Care in Ethiopia for primary health care managers and program directors over the course of five days (International Institute of Primary Health Care in Ethiopia, 2017).

The findings reported in this study are a part of a comprehensive evaluation conducted to determine the effectiveness and efficiency of LMG trainings. The need to redesign training content and approach will be considered to publish in peer-reviewed journals subsequently. The aim of this study was to determine the effectiveness of leadership, management and governance competencies on performance improvement at primary health care entities using the modified Kirkpatrick \& Kirkpatrick (2006) conceptual map of training evaluation (Armstrong, 2009) through implementation over the course of a one-year period.

\subsection{Objective of the Study}

The general objective of this study was to evaluate the effectiveness and efficiency of approaches of the basic LMG trainings for health managers in USAID Transform: Primary Health Care project-targeted woredas in the four agrarian 
regions of Ethiopia.

The specific objectives of this study were to:

- Investigate the effectiveness of the basic LMG trainings implemented in primary health care facilities in Ethiopia.

- Compare the outputs of the two types of basic LMG training modalities (block and segmented) implemented in primary health care facilities.

\section{Hypothesis}

The following two hypotheses were constructed based on the study objectives:

HO1: There is no statistically significant difference between the mean knowledge score before and after basic LMG training.

HO2: There is no statistically significant difference between the block and segmented basic LMG training approaches.

\section{Materials and Methods}

\subsection{Study Design}

This study employed a prospective, an interventional a before and after survey design (Creswell \& Plano Clark, 2011; Bowling, 2014; Bullock, 2017) and was conducted between August 28, 2017, and September 30, 2018, in Amhara, Oromia, SNNP, and Tigray regions of Ethiopia. Kirkpatrick \& Kirkpatrick's (2006) model is well known for the analysis and evaluation of training and educational programs. In addition, it considers the different styles of training, both formal and informal, and is useful to determine aptitudes based on its four levels of criteria (Kurt, 2016). Therefore-for this study-a modified Kirkpatrick \& Kirkpatrick's (2006) model of training evaluation (Alvarez et al., 2004; Armstrong, 2009) was used as a guiding framework for the data collection, analysis, and interpretation (Figure 1).

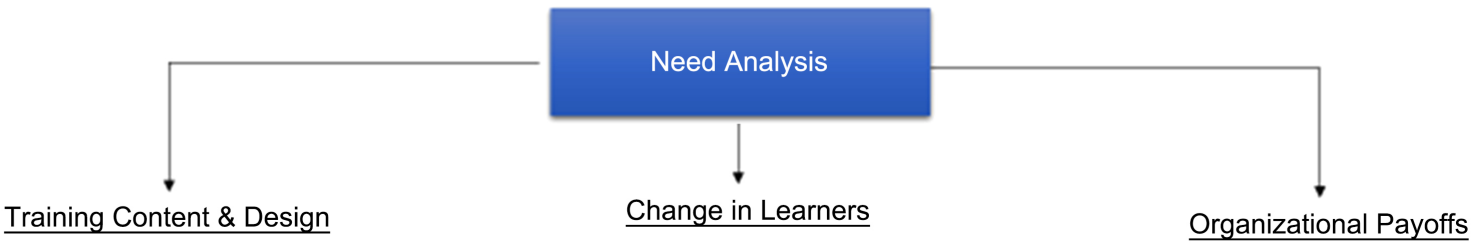

\section{Duration of the training Modules, \\ Units, Sessions or sub Sessions Training objectives}

Reactions

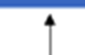

Individual Characteristics

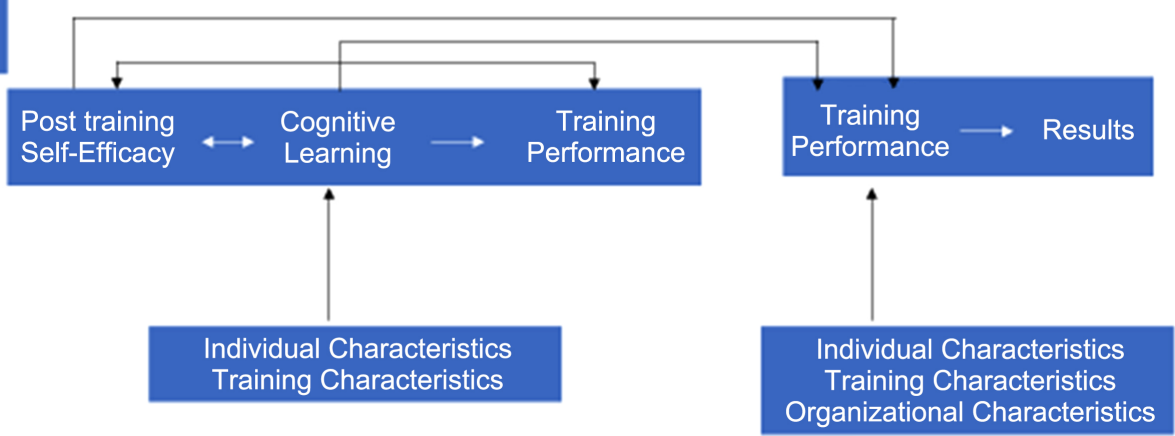

Figure 1. Conceptual map of LMG training evaluation (Armstrong, 2009; Kurt, 2016). 
A conceptual map was adopted to evaluate leadership, management and governance trainings and interventions in Ethiopia. The framework depicts the relations between self-efficacy, cognitive learnings and training performances with individual and organizational factors in contributing for better health outcomes.

\subsection{Study Setting}

USAID Transform: Primary Health Care Activity is being implemented in four agrarian regions of Ethiopia, (Amhara, Oromia, SNNP, and Tigray) (Figure 2). According to the health and health-related indicators of Ethiopia 2016, the 77 million inhabitants of these regions represent $85.9 \%$ of the national population $(\mathrm{FMOH}, 2016)$. Each region is subdivided into zones and woredas which are the smallest government administration units. The project works in $300(43.7 \%)$ woredas; $76(45.2 \%)$ of which are in Amhara; 135 (44.8\%) are in Oromia; 70 (42.4\%) are in SNNP; and 19 (36.5\%) are in Tigray regions. The four regions have 76 primary hospitals; 1531 health centers; and, 7562 health posts (USAID Transform: Primary Health Care, 2017b). In 2017, through the direct support of the project, $24(8.0 \%)$ of districts had LMG trained healthcare workers and managers at all primary health care entities (USAID Transform: Primary Health Care, 2017b). One hundred and thirty-six health facility teams were recruited and enrolled in this study. The teams were exposed to an "integrated leading and managing for result" model. Each trainee was given the opportunity to self-assess their LMG knowledge and skills. An equal number of non-trained staff had opportunity to rate their organization's leadership, management and governance culture before and after the interventions.

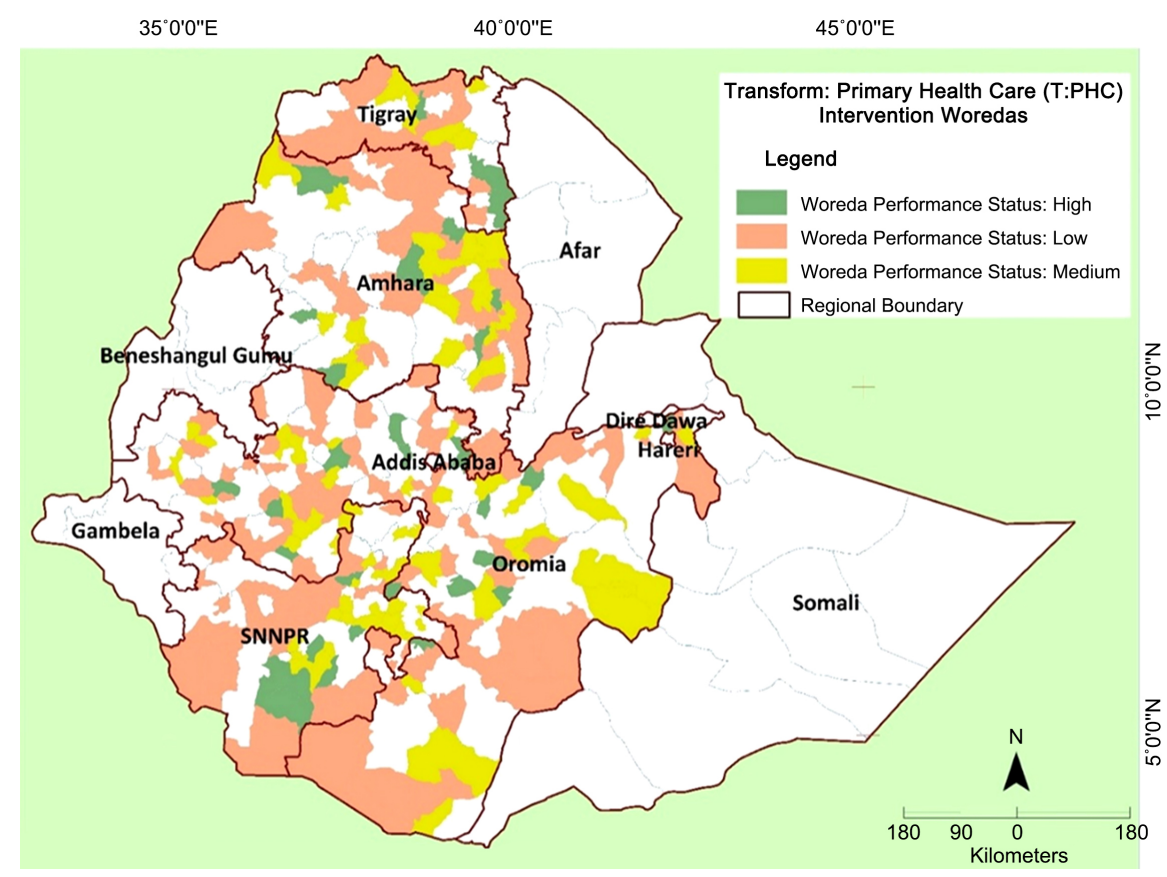

Figure 2. Map of Ethiopia showing USAID Transform: Primary health care project supported districts. 
Map of Ethiopia depicting the USAID Transform: Primary Health Care Activity supported districts. The green colored districts are high performers, yellow colored districts are medium performers and red colored districts are low performers in terms of maternal and child health indicators.

\subsubsection{Adoption of Leadership, Management and Governance Training and Interventions}

Based on the lessons from national experiences, the USAID Transform: Primary Health Care Activity developed a blocked and segmented training package with subsequent six to nine-month leadership projects to reach staff at primary health care facilities. The project developed and implemented LMG trainings and interventions using nationally endorsed course materials that allowed trainees to earn 78 continuing education units upon completion (FMOH, 2017). The five-course modules include: 1 ) introduction to health systems; 2 ) introduction to leadership, management and governance; 3) improving performance through enhanced leadership, management, and governance; 4) resource management; and, 5) health service delivery management. Each module consists of units, sessions, and sub-sessions designed to achieve desired competencies. These practices are: four leading practices, (scanning; focusing; aligning and mobilizing; inspiring); four managing practices, (planning; organizing; implementing; monitoring and evaluating); and, five governing practices, (cultivating accountability; engaging stakeholders; setting shared goals; stewarding resources; continuous governance enhancement).

\subsubsection{Basic LMG Trainings and Coaching Interventions}

USAID: Transform: Primary Health Care Activity facilitated the two training modality option blocks i.e. those administered all at once, and segmented blocks i.e. those that were broken into a certain number of days over a period of time, for each of the five-course modules. From June $8^{\text {th }}$ to September $30^{\text {th }}, 2017$, ten-block and fourteen segmented basic LMG trainings were facilitated and baseline measurements were taken. The LMG trainings were conducted in 24 districts with a total of 555 trainees. The details of participants in each category and region are presented in Table 1.

Table 1. Participants trained using the two models of LMG, (by region and sex), September 2018 .

\begin{tabular}{|c|c|c|c|c|c|c|}
\hline \multirow{2}{*}{ Region } & \multirow{2}{*}{$\begin{array}{c}\text { \# of } \\
\text { districts }\end{array}$} & \multicolumn{2}{|c|}{$\begin{array}{l}\text { \# of districts by LMG } \\
\text { trainings approaches }\end{array}$} & \multicolumn{3}{|c|}{ \# participants } \\
\hline & & $\begin{array}{l}\text { Block } \\
\text { course }\end{array}$ & $\begin{array}{l}\text { Segmented } \\
\text { course }\end{array}$ & Male & Female & $\begin{array}{c}\text { Total } \\
(\mathrm{M}+\mathrm{F})\end{array}$ \\
\hline Amhara & 6 & 3 & 3 & 112 & 18 & 130 \\
\hline Oromia & 5 & 2 & 3 & 83 & 20 & 103 \\
\hline SNNP & 7 & 3 & 4 & 189 & 37 & 226 \\
\hline Tigray & 6 & 2 & 4 & 79 & 17 & 96 \\
\hline Total & 24 & 10 & 14 & 463 & 92 & 555 \\
\hline
\end{tabular}


Based on the national course syllabus (S1 File 1), trainees are informed about the priority of health area, and concept of leadership, management and governance for result are covered. During the classroom trainings, the LMG core teams developed projects using a tool named the Challenge Model (MSH, 2005). This tool helped the core LMG teams face their organizational challenges through developing performance improvement projects by reviewing their organizational mission and strategic priorities; develop a shared vision for the future that contributes to the accomplishment of the organizational mission or strategic priorities; define one measurable result that can be achieved in a short amount of time; assess the current situation to take an accurate baseline measurement; identify the obstacles and root causes using a fishbone analysis, the why technique or workflow analysis which helps the core LMG teams reach the stated desired result; define challenges in light of the root causes and select priority actions; developed an action plan that estimates the human, material and financial resources needed and timeline for implementing the actions; and implement the plan and monitor and evaluate progress towards achieving the desired results (MSH, 2005).

The core LMG teams organized staff meetings to go through the components of the Challenge Model within their respective workplaces. The performance improvement projects which involve the buy-in by all inspired staff were implemented for six-to-nine months, during which each team received three or four on-site coaching sessions (FMOH, 2017). The intended outcomes of the performance improvement projects included developing the leading, managing, and governing competencies of health workers at all levels and building services which are accessible for more people in the communities. Some of the performance improvement projects targeted an increasing the number of institutional deliveries; the proportion of modern contraceptive users; and the number of primary health care facilities that meet the standards of the Ethiopian Hospital Service Transformation Guidelines (S2 File 2). The performance improvement projects also helped trainees use LMG training concepts to identify and solve challenges at the workplace. After implementation, each performance improvement project team was assessed against their intended targets. From $25^{\text {th }}$ December 2017 to $30^{\text {th }}$ March 2018, the assessment team, comprised of LMG experts from participating in-service training institutions, zonal health departments, and the USAID Transform: Primary Health Care Activity, appraised the performance of each team and helped the core LMG team present its findings and results at organized knowledge sharing events.

\subsection{Target Population}

The study targeted two groups of the population, namely: LMG trained health workers, and non-trained health workers employed in the four intervention targeted regions. Trained health workers and managers with the support of the USAID Transform: Primary Health Care project were targeted to measure their 
knowledge and skills on LMG practices, gained as a result of the intervention. LMG trained and non-trained health workers with perceived changes in management systems, work climate, and responsiveness of the health system to new challenges were measured before and after the intervention.

\subsection{Eligibility Criteria}

All study participants work in USAID Transform: PHC Activity's LMG intervention targeted primary health care entities. All basic LMG trainees and non-trained staff in the public health sector who volunteered to participate and those that had completed the pre-post training interviews were targeted. Health workers in facilities not targeted for the LMG intervention, health workers who did not volunteer to participate and health workers who had not completed the pre-post interviews were excluded from the study.

\subsection{Sampling Size and Sampling}

All twenty-four LMG training and interventions targeted districts were purposively selected and two different sample sizes were calculated.

\subsubsection{Sample Size Determination for LMG Trainees}

The first sample size (n) for number of LMG trainees was calculated using Slovin's formula (Tejda \& Punzalan, 2012), Since, the population and their distribution is too large to sample:

$$
\mathrm{n}=\mathrm{N} / 1+\mathrm{N}(\mathrm{e})^{2}
$$

where:

$\mathrm{n}$ = designates sample size for the study; $\mathrm{N}=$ designates total number of employees; $\mathrm{e}=$ designates maximum variability or margin of standard error at $95 \%$ confidence interval; and $1=$ designates the probability of the event occurring.

Therefore: the estimated sample size for the trained group 233; and considering $25 \%$ for non-response, refusal, and dropout, it makes the sample size-293 (Pagano \& Gauvereau, 2000). The sample size was allocated based on the number of trainees in each intervention district and a simple random sampling technique was used to enroll participants.

\subsubsection{Sample Size Determination for Non-LMG Trainees}

The second sample size (ni) for non-trained staff was calculated using a single population proportion formula (Daniel, 2009).

Where, ni is sample size, $\mathrm{p}$ is the proportion of LMG non-trained staff who have the desired knowledge on thirteen practices, and $\mathrm{d}$ is the margin of error.

In addition, the following assumption was used: since $\mathrm{p}$ is $0.50 \%(p=0.50, \mathrm{q}=$ 0.50 ), allowing $5 \%$ for expected margin of error (d) with $95 \%$ confidence level ( $\mathrm{Z}$ $\alpha / 2=1.96$ ), the required sample size ni is 384 . The sample size was distributed based on population proportion to the size of LMG trainees and a simple random sampling technique was used to enroll non-trained staff in targeted health facilities. 


\subsection{Data Collection}

The data were collected from basic LMG trainees and non-trained staff working in intervention primary health care entities using interviewer-administered and self-administered structured questionnaires, respectively. The questionnaires were prepared after a thorough review of relevant literature and the national leadership, management, and governance in-service training materials for hospitals and health center managers (Wiseman, 2011; FMOH, 2017; Mutale et al., 2017). The questionnaires have two major parts. The first part is dedicated for LMG knowledge and skill survey tools. The second part is dedicated to capture the health systems strengthening survey tools. The details of each tools are presented below.

Sixteen data collectors, each with clinical, health management, social science, or public health training were recruited. Data collectors and supervisors were trained on ethical principles, data collection tools, and interviewing techniques. Before the actual data collection started, all tools were piloted in USAID Transform: Primary Health Care Activity-supported woredas and were amended accordingly.

\subsubsection{Leadership, Management and Governance Knowledge and Skill Survey}

Data were collected to monitor post-training self-efficacy, cognitive learning, and training performances. The pre-post measurements were designed to capture the knowledge and skills of LMG trained health workers on thirteen leadership, management and governance practices. Similarly, the baseline and end-line performance improvement project achievements were rated using trained LMG coaches. Certified LMG training facilitators and project staff supervised all data collectors. The principal investigators and supervisors checked the completeness and consistency of each filled questionnaire and made corrections on a daily basis.

The questionnaires for basic LMG trainees had four sections: 1) instruction and consent to participate; 2) sociodemographic characteristics of participants; and, 3) organizational culture rating tool; 4) document review using data abstraction for scores of each trainee captured during classroom before and after course tests, and performance improvement project measurements at baseline and end-line.

\subsubsection{Health Systems Strengthening Survey}

Eighteen questions with a 10-point Likert scale (Likert, 1932) were used to measure responses to statements presented on: strengthened management systems (9 items); enhanced work climate (5 items); and responsiveness or capacity of the health system to overcome new challenges (4 items). The sample questionnaire for each category is presented in Box 1. To measure the changes in LMG practices of trainees, a tool was used to assess their perceived practices before and after the basic LMG training was offered to them. The respondents were LMG 
Box 1. Sample questionnaires.

\begin{tabular}{ccc}
\hline Serial no. & Sample tool & Category \\
\hline WC1 & $\begin{array}{c}\text { In this office, employees understand the } \\
\text { organizational structure and reporting lines of } \\
\text { their unit/department and how their job } \\
\text { functions relate to overall departmental } \\
\text { objectives and goals. }\end{array}$ & $\begin{array}{c}\text { Strengthened management } \\
\text { systems. }\end{array}$ \\
WC10 & $\begin{array}{c}\text { My contributions at work are acknowledged } \\
\text { and appreciated. }\end{array}$ & Enhanced work climate. \\
WC13 & $\begin{array}{c}\text { In this office, supervisors delegate } \\
\text { challenging assignments to assistants, } \\
\text { which helps them to develop their } \\
\text { skills and expertise. }\end{array}$ & $\begin{array}{c}\text { Responsiveness or capacity } \\
\text { of health system to overcome } \\
\text { new challenges. }\end{array}$ \\
\hline
\end{tabular}

trainees and non-trained health workers operating within the intervention area's primary health care entities. These were adapted from the United Kingdom's clinical leadership competency framework as cited in Mutale et al. (2017). The questionnaire was developed in English and translated into local languages (i.e., Amharic, Afan Oromo, and Tigrigna), then translated back into English.

\section{Validation of organizational LMG culture measurements}

The questionnaires for non-trained staff had three sections: 1) instruction and consent to participate; 2) sociodemographic characteristics of participants; and, 3) organizational culture rating tool. The results of these data were used by researchers to validate the knowledge and skills of LMG trainees.

\subsection{Data Analysis}

The data were analyzed using SPSS IBM version 20 (SPSS Inc., 2011). The tools' internal reliability was assessed using Cronbach's alpha values (Gershon et al., 2004). According to Bland and Altman (1997), if the Cronbach's alpha value score is more than 0.7 , the scale can be considered reliable. The tools have 18 questions in three categories, namely: nine questions on strengthened management systems, five questions on enhanced work climate, and four questions on the capacity to respond to changes. The reliability test results were 0.839 for work climate, 0.895 for strengthened management systems, and 0.886 for the capacity to respond to changes, which showed the scale used was internally consistent and reliable.

A statistical test using multi-collinearity analysis through determining the variance inflation factor (VIF) was run to check the tools' divergent validity (Bowling, 2014). According to Menard (1995), if the VIF reported value exceeds 10 , it implies the associated regression coefficients are poorly estimated because of multi-collinearity. In this pilot study, the collinearity test VIF results were: 1.018 for work climate, 2.94 for strengthened management systems, and 6.443 for capacity respond to new challenges and no VIF value exceeded 10. Hence, 
there was no observed serious multi-collinearity affecting the regression coefficient.

Descriptive statistics were employed using frequencies, tables, and graphs. In addition, a linear regression was used to test the relationship between each dependent, and independent variable. Paired sample t-test and analysis of variance (ANOVA) were conducted to check whether there were significant differences in mean values by individual and organizational characteristics. Multivariable linear regression analysis was used to identify the predictors of LMG training effectiveness.

\subsection{Ethical Considerations}

Ethical clearance was obtained from four regional institutional review boards. Ethical clearances were granted by the Amhara Public Health Institute (Ref No. HRTT02/137/2018), the Oromia Regional State Health Bureau (Ref No. BEFO/ HBTPH/1-8/476), the SNNP Regional State Health Bureau (Ref No. PLMG-19/ 8407), and the Tigray Regional State Health Bureau's (Ref No. 453/1418/10) institution review boards and research ethics committees. Data were collected after getting full informed consent from each participant and facility manager. Privacy, anonymity, and confidentiality were maintained throughout the data collection, analysis, and report writing activities. The study had no known risk and no payment was made to participants.

\section{Results}

Table 2 presents the statistical summary of the socio-demographic data collected from trainees. One-hundred and three trainees, (35.2\%) were recruited from the SNNP region; $62.5 \%$ of study participants, (183) are between 26 and 35 years of age, and the mean age with standard deviation (SD) was $29.9 \pm 6.9$ years. The majority, (222/75.8\%) of the study participants were male. Seventy, (58.0\%) were nurses who had worked in the profession for an average of 7.6 years.

Table 3 below presents the socio-demographic characteristics of non-LMG trained staff in selected health facilities. The majority, (75.1) were male, and 78.7\% of participants fall under the age category of 26 - 35 years. One-hundred-thirty-six randomly selected health facilities: 21 (15.6\%) from Tigray, 35 (25.2\%) from Oromia, 37 (27.4\%) from Amhara, and 43 (31.9\%) from SNNP regional states were included in the study. One-hundred-and eleven (82.2\%) were health centers, $12(8.9 \%)$ were primary hospitals, 11 were district health offices and 2 were zonal health departments.

\subsection{Knowledge Change before and after LMG Training}

The LMG trainees' mean pretest knowledge score with SD was $44.97 \% \pm 15.50 \%$. Their post-test score was $78.11 \% \pm 14.22 \%$, which showed a significant gain in knowledge at post-test with $\mathrm{t}=-35.99, \mathrm{df}=292, p<0.001$. In this study, $80.9 \%$, (237) of trainees scored greater or equal to $70 \%$ on the post-test. 
Table 2. Socio-demographic characteristics of basic LMG trainees $(n=292)$, September 2018.

\begin{tabular}{|c|c|c|c|}
\hline Variable & Characteristics & Frequency & Percent \\
\hline \multirow{5}{*}{ Region } & Tigray & 31 & 10.6 \\
\hline & Amhara & 77 & 26.3 \\
\hline & & & \\
\hline & Oromia & 82 & 28.0 \\
\hline & SNNP & 103 & 35.2 \\
\hline \multirow{3}{*}{ Sex } & Male & 222 & 75.8 \\
\hline & & & \\
\hline & Female & 71 & 24.2 \\
\hline \multirow{5}{*}{ Age } & $<25$ years & 65 & 22.2 \\
\hline & $26-35$ years & 183 & 62.5 \\
\hline & $36-45$ years & 28 & 9.6 \\
\hline & $46+$ years & 17 & 5.8 \\
\hline & \multicolumn{3}{|c|}{$\begin{aligned} \text { Mean } \pm \mathrm{SD}= & 29.9 \pm 6.9 \text { years; } \text { median }=28 \text { years; } \\
& \text { and range }=39 \text { years }\end{aligned}$} \\
\hline \multirow{5}{*}{ Profession } & Nurse & 170 & 58.0 \\
\hline & Health officer & 65 & 22.2 \\
\hline & Midwife (BSc and diploma) & 30 & 10.2 \\
\hline & Health services management & 14 & 4.7 \\
\hline & $\begin{array}{l}\text { Other (lab, pharmacy, environmental } \\
\text { health professional) }\end{array}$ & 14 & 4.7 \\
\hline \multirow{5}{*}{ Salary } & $<3500 \mathrm{ETB}^{*}$ & 92 & 31.4 \\
\hline & $3501-6860$ ЕТВ & 143 & 48.8 \\
\hline & $6861-10,219$ ETB & 52 & 17.7 \\
\hline & $10,220+\mathrm{ETB}$ & 6 & 2.0 \\
\hline & \multicolumn{3}{|c|}{$\begin{array}{c}\text { Mean } \pm \mathrm{SD}=4869.9 \pm 2264.6 \mathrm{ETB} ; \text { median }=4085 \mathrm{ETB} \\
\text { and range }=13,579 \mathrm{ETB}\end{array}$} \\
\hline \multirow{3}{*}{ Years of service } & $<3$ years & 76 & 25.9 \\
\hline & $4+$ years & 217 & 74.1 \\
\hline & \multicolumn{3}{|c|}{ Mean $\pm \mathrm{SD}=7.6 \pm 7.1$ years; median $=5$ years; and range $=37$ years } \\
\hline \multirow{2}{*}{ Training type } & Segmented course & 178 & 60.8 \\
\hline & Block course & 115 & 39.2 \\
\hline
\end{tabular}

B: ${ }^{\star} 1$ USD $=27.90$ Ethiopian birr. 
Table 3. Socio-demographic characteristics of non-trained staff $(n=333)$, September 2018.

\begin{tabular}{|c|c|c|c|}
\hline Variable & Characteristics & Frequency & Percent \\
\hline \multirow{3}{*}{ Sex } & Male & 250 & 75.1 \\
\hline & & & \\
\hline & Female & 83 & 24.9 \\
\hline \multirow{5}{*}{ Age } & $<25$ years & 12 & 3.6 \\
\hline & $26-35$ years & 262 & 78.7 \\
\hline & 36 - 45 years & 37 & 11.1 \\
\hline & $46+$ years & 22 & 6.6 \\
\hline & \multicolumn{3}{|c|}{ Mean $\pm \mathrm{SD}=31.74 \pm 6.63$ years; median $=30$ years; and range $=36$ year } \\
\hline \multirow{5}{*}{ Profession } & BSc nurse & 49 & 14.7 \\
\hline & BSc public health officer & 75 & 22.5 \\
\hline & Diploma nurse & 152 & 45.6 \\
\hline & Midwifery (BSc and diploma) & 30 & 9.0 \\
\hline & Health services management & 12 & 4.5 \\
\hline \multirow{4}{*}{ Organization } & Health center & 111 & 82.2 \\
\hline & Primary hospital & 12 & 8.9 \\
\hline & Woreda health office & 11 & 7.4 \\
\hline & Other (zonal health department) & 2 & 1.5 \\
\hline
\end{tabular}

\subsection{Performance Change at Baseline and End-Line Survey}

Of the developed 136 performance improvement projects, 53, (38.9\%) were on delivery services. Twenty-five, (18.5\%) focused on family planning, and 25, (18.5\%) on health system strengthening (Figure 3). All 136 core LMG teams were assessed; the mean performance improvement project baseline score with SD was $38.35 \pm 24.79$ units and the mean end-line score with SD was $52.22 \pm$ 26.23 units. The majority, (252/86.0\%) of trainees completed their performance improvement projects and achieved $80.0 \%$ or more of their desired measurable results. As a result of these projects, 2290.6 units of desired measurable results were gained. The average net gain by each entity was 16.55 (95\% CI: 12.26, $20.84)$ with $S D( \pm 17.59)$ units. The results gained, with paired sample $t$-test $t=$ $-12.28, \mathrm{df}=292, p<0.001$, was statistically significant.

Figure 4 depicts the proportion of trainees who scored $>70 \%$ in the post-test and $>80 \%$ in leadership projects. The results of the theory showed that trainees from block LMG trainings had a higher score, with a borderline significant difference at $\mathrm{X}^{2}=5.61 . p=0.06$. Similarly, the results of the end-line performance improvement or leadership project evaluation showed that trainees of the block 


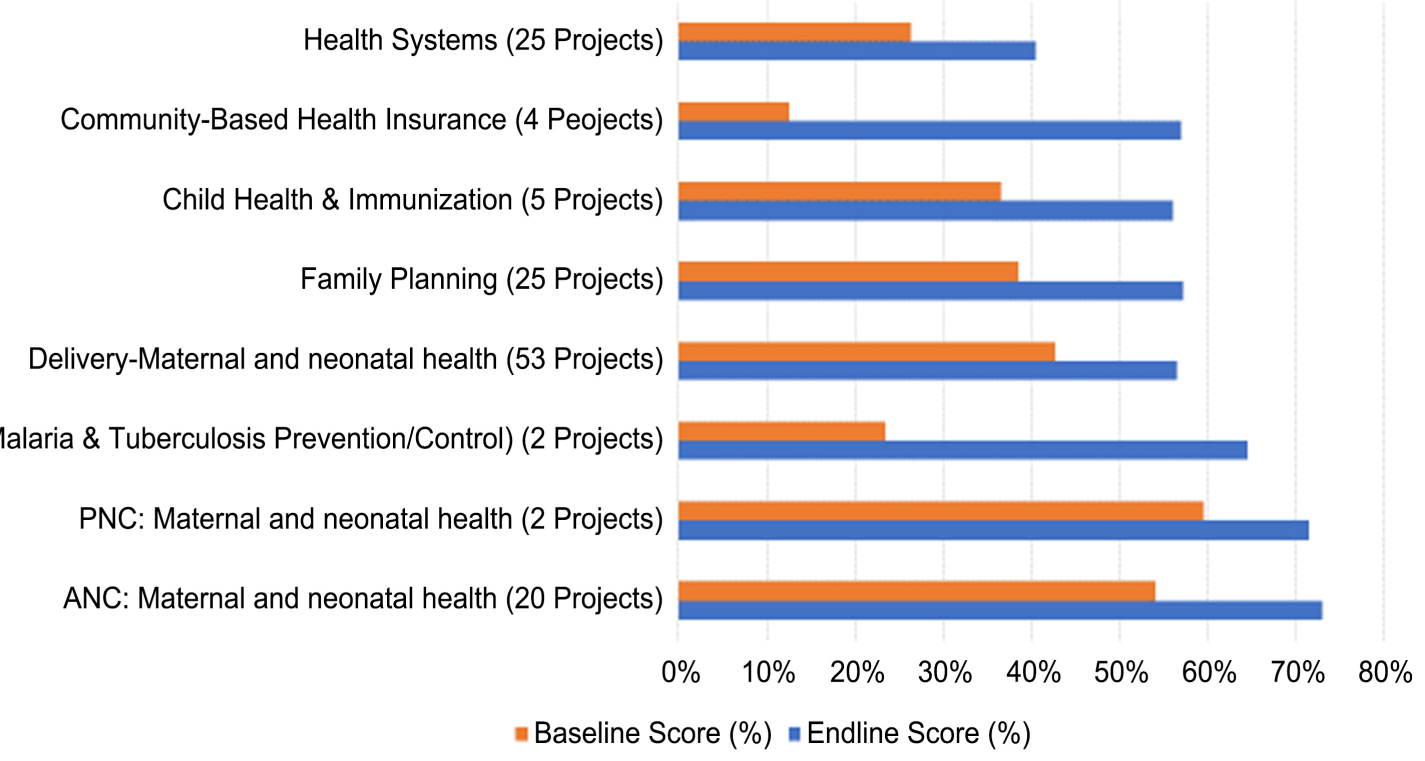

Figure 3. Proportion of health service coverage change by program categories, September 2018.

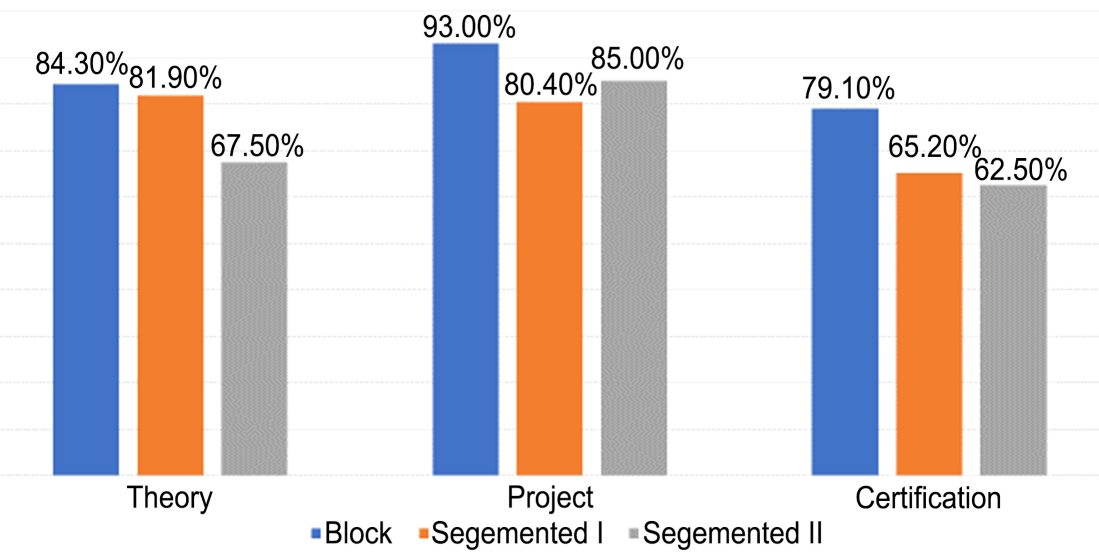

Figure 4. Certification of trainees after completion of course, September 2018.

LMG packages had a higher score, with a statistically significant difference at Chi-square $=8.32, p=0.01$. Certification showed that more block LMG trainees completed the course than segmented trainees, with a statistically significant difference at Chi-square $=7.16, p=0.02$.

\subsection{Health System Improvement}

Table 4 depicts health system improvements observed as a result of implementing basic LMG training interventions. Trainees were assessed and measured on levels of management system improvements, enhanced work climate, and responsiveness of the health system to face new challenges. The mean perceived pre- and post-training scores on strengthening management systems with SD were $5.75 \pm 233$ and $8.03 \pm 1.44$, respectively. This perceived assessment revealed a significant improvement at post-training, with $\mathrm{t}=-18.54 \mathrm{df}=292, p<0.001$. Similarly, the average pre-and post-training scores on enhanced work climate 
Table 4. Work climate, management system strength, and ability to respond to new challenges before and after assessment of LMG trained and non-trained staff, September 2018.

\begin{tabular}{|c|c|c|c|c|c|}
\hline Serial no. & Characteristics & $\begin{array}{r}\text { Trainees } n=293 \\
\text { before mean } \pm S D\end{array}$ & $\begin{array}{l}\text { Trainees } n=293 \\
\text { after mean } \pm S D\end{array}$ & $\begin{array}{c}\text { Staff } n=333 \\
\text { before mean } \pm S D\end{array}$ & $\begin{array}{c}\text { Staff } n=333 \\
\text { after mean } \pm S D\end{array}$ \\
\hline WC1 & $\begin{array}{l}\text { In this office, employees understand the } \\
\text { organizational structure and reporting lines of } \\
\text { their unit/department, and how their job functions } \\
\text { relate to overall departmental objectives and goals. }\end{array}$ & $4.88 \pm$ SD 1.92 & $7.88 \pm$ SD 1.68 & $5.88 \pm \mathrm{SD} 2.35$ & $7.10 \pm$ SD 2.37 \\
\hline WC2 & $\begin{array}{l}\text { For most meetings in this office, agendas are } \\
\text { circulated to all before the meeting. }\end{array}$ & $7.00 \pm$ SD 2.64 & $7.63 \pm$ SD 2.52 & $5.47 \pm$ SD 2.99 & $7.22 \pm \mathrm{SD} 6.07$ \\
\hline WC3 & $\begin{array}{l}\text { For most meetings in this office, minutes are } \\
\text { circulated to all soon after the meeting, } \\
\text { indicating follow-up items. }\end{array}$ & $6.01 \pm$ SD 2.79 & $8.13 \pm$ SD 2.19 & $6.43 \pm$ SD 2.97 & $7.14 \pm$ SD 3.02 \\
\hline WC4 & $\begin{array}{l}\text { The leadership here keeps staff well informed } \\
\text { about what is going on within the organization. }\end{array}$ & $5.90 \pm \mathrm{SD} 2.30$ & $8.08 \pm$ SD 1.99 & $6.00 \pm \mathrm{SD} 2.58$ & $6.89 \pm$ SD 2.75 \\
\hline WC5 & $\begin{array}{l}\text { In this office, cooperation and teamwork } \\
\text { between staff in different units is encouraged. }\end{array}$ & $8.25 \pm$ SD 1.70 & $8.24 \pm$ SD 1.84 & $6.47 \pm$ SD 2.64 & $749 \pm$ SD 2.47 \\
\hline WC6 & $\begin{array}{l}\text { In this office, we are encouraged to } \\
\text { use data to guide decision-making, } \\
\text { priority-setting, and planning. }\end{array}$ & $6.22 \pm \mathrm{SD} 2.30$ & $8.25 \pm$ SD 1.70 & $6.32 \pm$ SD 2.47 & $7.58 \pm$ SD 2.41 \\
\hline WC7 & $\begin{array}{l}\text { In this office, we are encouraged to analyze } \\
\text { problems carefully to understand root causes } \\
\text { before deciding on solutions }\end{array}$ & $5.68 \pm$ SD 2.22 & $7.97 \pm$ SD 1.87 & $6.01 \pm$ SD 2.48 & $7.01 \pm$ SD 2.67 \\
\hline WC8 & $\begin{array}{l}\text { In this office, formal individual performance } \\
\text { appraisals are routinely conducted on an } \\
\text { annual basis. }\end{array}$ & $7.02 \pm$ SD 2.72 & $8.45 \pm$ SD 2.01 & $7.95 \pm$ SD 2.40 & $8.28 \pm$ SD 2.20 \\
\hline WC17 & $\begin{array}{l}\text { In this office, supervisors take appropriate corrective } \\
\text { actions when an employee is not performing well. }\end{array}$ & $5.81 \pm \mathrm{SD} 2.40$ & $7.69 \pm$ SD 2.09 & $6.59 \pm$ SD 2.55 & $7.44 \pm$ SD 2.61 \\
\hline & Overall strengthening management system & $5.75 \pm$ SD 2.33 & $8.03 \pm$ SD 1.44 & $6.34 \pm$ SD 1.87 & $7.35 \pm$ SD 2.01 \\
\hline WC9 & $\begin{array}{l}\text { In this office, supervisors provide constructive } \\
\text { feedback to their assistants on a regular basis, } \\
\text { to help improve job performance. }\end{array}$ & $7.80 \pm \mathrm{SD} 2.12$ & $7.98 \pm$ SD 2.02 & $6.32 \pm \mathrm{SD} 2.46$ & $7.51 \pm \mathrm{SD} 2.37$ \\
\hline WC10 & $\begin{array}{c}\text { My contributions at work are acknowledged } \\
\text { and appreciated. }\end{array}$ & $5.82 \pm \mathrm{SD} 2.3 .2$ & $7.80 \pm$ SD 2.12 & $5.78 \pm$ SD 2.56 & $7.20 \pm$ SD 2.53 \\
\hline WC11 & $\begin{array}{l}\text { My supervisor works with me to identify my } \\
\text { training needs and ensures I get the training } \\
\text { or mentorship I need to do my job effectively. }\end{array}$ & $5.55 \pm \mathrm{SD} 2.38$ & $7.71 \pm$ SD 2.08 & $5.57 \pm \mathrm{SD} 2.65$ & $7.16 \pm$ SD 2.44 \\
\hline WC16 & $\begin{array}{l}\text { In this office, supervisors do everything in their } \\
\text { power to help resolve HR issues (such as } \\
\text { confirmation) in a timely manner. }\end{array}$ & $5.57 \pm S D 2.25$ & $7.63 \pm S D 2.28$ & $6.31 \pm S D 2.62$ & $7.35 \pm$ SD 2.56 \\
\hline \multirow[t]{2}{*}{ WC18 } & $\begin{array}{l}\text { In this office, supervisors maintain a high } \\
\text { standard of ethics and accountability. }\end{array}$ & $6.47 \pm \mathrm{SD} 2.36$ & $8.13 \pm S D 2.02$ & $6.64 \pm$ SD 3.03 & $7.70 \pm$ SD 2.35 \\
\hline & Overall work climate enhancement & $5.75 \pm$ SD 1.85 & $7.88 \pm$ SD 1.64 & $6.12 \pm$ SD 1.96 & $7.38 \pm$ SD 1.82 \\
\hline
\end{tabular}




\section{Continued}

\begin{tabular}{|c|c|c|c|c|c|}
\hline WC12 & $\begin{array}{l}\text { At this office, when staff attend trainings, } \\
\text { efforts are made to ensure that they apply } \\
\text { what they have learned back at the job site. }\end{array}$ & $5.57 \pm \mathrm{SD} 2.25$ & $8.00 \pm$ SD 1.78 & $6.23 \pm \mathrm{SD} 2.43$ & $7.54 \pm$ SD 2.44 \\
\hline WC13 & $\begin{array}{l}\text { In this office, supervisors delegate challenging } \\
\text { assignments to assistants, which helps them to } \\
\text { develop their skills and expertise. }\end{array}$ & $5.33 \pm \mathrm{SD} 2.14$ & $7.52 \pm$ SD 2.06 & $5.76 \pm \mathrm{SD} 2.55$ & $7.70 \pm$ SD 2.48 \\
\hline WC14 & $\begin{array}{c}\text { In this office, when giving out special assignments, } \\
\text { supervisors clearly communicate expectations at } \\
\text { the beginning and check in on progress, } \\
\text { without micromanaging. }\end{array}$ & $5.60 \pm$ SD 2.19 & $7.74 \pm$ SD 1.98 & $6.15 \pm \mathrm{SD} 2.58$ & $7.38 \pm$ SD 2.38 \\
\hline \multirow[t]{2}{*}{ WC15 } & $\begin{array}{l}\text { In this office, supervisors or unit leaders regularly } \\
\text { monitor progress and hold each staff accountable } \\
\text { for following through on assigned tasks related } \\
\text { to work plans. }\end{array}$ & $5.96 \pm \mathrm{SD} 2.32$ & $8.08 \pm$ SD 2.03 & $6.62 \pm \mathrm{SD} 2.38$ & $7.85 \pm$ SD 2.27 \\
\hline & Overall Responsiveness to new challenges & $5.64 \pm \mathrm{SD} 1.92$ & $7.81 \pm \mathrm{SD} 1.62$ & $6.19 \pm \mathrm{SD} 1.95$ & $7.61 \pm$ SD 1.90 \\
\hline
\end{tabular}

NB: Enhanced work climate (\#5): WC 9, WC 10, WC11, WC16, and WC18; management system strengthening (\#9): WC1, WC2, WC3, WC4, WC5, WC6, WC7, WC8, and WC17; and responsiveness to change (\#4): W12, W13, W14, and W15.

were SD of $5.75 \pm 1.85$ and $7.88 \pm 1.64$, respectively. This result showed a statistically significant improvement at post-training, with $\mathrm{t}=-23.97, \mathrm{df}=292, p<$ 0.001 . Moreover, the average pre-and post-training scores on capacity to respond to new challenges (responsiveness) with SD were $5.64 \pm 1.92$ and $7.81 \pm$ 1.62 , respectively. This result showed a statistically significant improvement at post-training, with $\mathrm{t}=-22.83, \mathrm{df}=292, p<0.001$. The overall pre- and posttraining health system improvement scores were $5.69 \pm 1.73$ and $7.93 \pm 1.43$, respectively. The score showed a statistically significant improvement with $\mathrm{t}=$ $-26.09, \mathrm{df}=292, p<0.001$ (Table 4).

\subsection{Validation of Leading, Managing and Governing Organizational Culture}

Three hundred and thirty-three non-trained staff were asked to measure their work climate, management systems, and health system responsiveness to new challenges before and after LMG trainings and interventions in their respective facility. The mean before and after training scores on strengthening management systems with SD were $6.34 \pm 1.87$ and $7.35 \pm 1.44$, respectively. This perceived assessment revealed a significant improvement at after-training, with $\mathrm{t}=$ $-11.99, \mathrm{df}=332, p<0.001$. Similarly, the average before and after training scores on enhanced work climate were reported with SD of $6.12 \pm 1.96$ and $7.38 \pm 1.82$, respectively. This result showed a statistically significant improvement at post-training, with $\mathrm{t}=-16.49, \mathrm{df}=332, p<0.001$. Moreover, the average pre-and post-training scores on the capacity to respond to a new challenge (responsiveness) with SD were $6.19 \pm 1.95$ and $7.61 \pm 1.90$, respectively. This result showed a statistically significant improvement at post-training, with $\mathrm{t}=-17.58, \mathrm{df}=332$, 
$p<0.001$. The overall before and after training health system improvement scores were $6.24 \pm 1.76$ and $7.51 \pm 1.74$, respectively. The score showed a statistically significant improvement with $\mathrm{t}=-17.09, \mathrm{df}=332, p<0.001$ (Table 4).

\section{Discussion}

This a before and after study was conducted to evaluate USAID Transform: Primary Health Care Activity-supported basic leadership, management, and governance training and interventions which were cascaded to primary health care workers and managers in the four regional states of Ethiopia. The LMG training included didactic, theoretical-based classroom training implemented either as a block or sequential training combined with subsequent implementation of performance improvement projects for six to nine months at the trainees' place of employment (FMOH, 2017). The knowledge and skills gained as a result of these trainings were demonstrated through pre-test, post-test, baseline, and end-line performance improvement project scores and continuing development of performance improvement projects in the health system. The results revealed that the LMG training and interventions had a positive impact on the performance of 136 primary health care entities. Furthermore, more than one-third of trainees had developed subsequent performance improvement projects. Hence, trainees confirmed the long-term effects of capacity enhancement on the performance of the health system. The results demonstrate the need to enhance the LMG competencies among health workers and managers, whose pre-service professional education is inclined to clinical care with limited coverage of leadership, management, and governance practices. Hence, without building the LMG competencies of health workers and managers, the health system may not deliver quality essential health services to the community. This in turn limits performance levels and can therefore lead to further frustration of health workers and health service managers. This was in keeping with the Uneke et al. (2012) finding in Nigeria, where training significantly increased policymakers' understanding of leadership and governance and improved human resource development, collaboration, system design, and accountability. Similarly, this finding corresponds with the Mutale et al. (2017) report on the catalyzing effects of leadership and management trainings on health system strengthening in Zambia.

The conceptual map and assumption of the LMG trainings were: enhancing knowledge and skills on leading, managing and governing practices of health workers and managers at primary health care entities will significantly improve the performance of individuals, teams, organizations and health systems for better health outcomes (LeMay \& Ellis, 2007; FMOH, 2017). For this study, the performance of basic LMG trainees was assessed by measuring trainees' after-training knowledge, skills, and behavioral patterns within primary health care facilities (AlYahya \& Norsiah, 2013). The majority of 235 (81\%) and 252 (86\%) of trainees scored above $70 \%$ on after training-test and $80 \%$ or more on the desired measurable results of their performance improvement projects, re- 
spectively. In addition, both trained and non-trained staff appreciated the positive impact of the knowledge and skills acquired by trainees on improving the management systems, work climate, and health system responsiveness to new challenges in their workplace. This finding was consistent with Packard and Jones (2015) who reported that after leadership development interventions, the on-job performance of participants and their supervisors were improved, and levels of self-efficacy significantly increased over time.

The evaluation indicated that trainees contributed to the improvement of primary health care service coverage over the 12 months of LMG interventions. This result was also attributed to the implementation of multi-faceted LMG interventions, which ranged from classroom trainings to leadership-project development and implementation. The performance improvements observed include improved management systems and work climate in the study areas. The findings also concur with La Rue et al. (2012), who assessed a leadership development program in Kenya by comparing baseline, end-line, and post-intervention data as well as with Rowe et al.'s (2018) systematic review, which reported professional health care provider practices improved using multiple strategies rather than by a single strategy. Similarly, Arinez et al. (2002) confer that good leadership and management practices improve the work climate, staff satisfaction, motivation, and performances.

\section{Limitations of the Study}

The major limitation of this study is related to the employed before and after non-experimental study design. Unlike a randomized study design, it is difficult to conclude the causal association between the LMG trainings and interventions with the resulting performance improvements. Despite this limitation, the investigators tried to ensure the relationship through collecting data from a longitudinal follow-up report, onsite coaching and developed agreed action plans. The study only targeted LMG training intervention sites, hence, before generalizing, the results should be interpreted based on the context. In addition, there were a significant number of non-responses among non-trained targeted staff.

\section{Summary}

Leadership, management, and governance trainings and interventions evaluation in different part of the world revealed its positive impact on performance and health care outcome improvement in a given health system. In this before and after LMG training evaluation, the knowledge and skills of trainees were significantly improved by $36.0 \%$. In addition, as a result of the leadership projects, each primary health care entity improved health service coverage by an average of $16.5 \%$. Among the LMG trainees, $70.0 \%$ (205/293) were successfully complete the national training requirements for certifications. While comparing the results, a higher and statistically significant scores were documented for blocked than segmented LMG training approaches. Furthermore, the evaluation showed 
a significant improvement in strengthening management system $(P<0.001$, enhancing work climate $(P<0.001)$ and responsiveness of the health system for new challenges $(P<0.001)$. Therefore, the LMG training and intervention supported by the USAID Transform: Primary health Care Activity was found to be effective.

\section{Conclusion and Recommendations}

The performance of the primary health care entities was significantly improved as a result of enhanced knowledge and skills through LMG trainings and interventions. Therefore, the basic LMG training and interventions were effective in enhancing the knowledge and skill of health workers. It is recommended that providing LMG trainings for more health workers and managers working at primary health care entities will accelerate the implementation of prioritized health sector interventions and is helpful in achieving the Sustainable Development Goals as a global target. An evaluation of the efficiency of the basic LMG training package is also recommended.

\section{Funding}

This study was fully funded by USAID under cooperative agreement AID-663A-17-00002 as part of the USAID Transform: Primary Health Care Activity in Ethiopia. The funding body had no role in the design, data collection, analysis, interpretation and writing stages of the study undertaking.

\section{Acknowledgements}

The investigators are indebted to all participants for their cooperation during data collection. In addition, the investigators are indebted to Heran Demissie for English language editing.

\section{Conflicts of Interest}

The authors declare no conflicts of interest regarding the publication of this paper.

\section{References}

Alvarez, K., Salas, E., \& Garofano, C. M. (2004). An integrated Model of Training Evaluation and Effectiveness. Human Resource Development Review, 3, 385-416. https://doi.org/10.1177/1534484304270820

AlYahya, M. S., \& Norsiah, B. M. (2013). Evaluation of Effectiveness of Training and Development: The Kirkpatrick Model. Asian Journal of Business and Management Sciences, 2, 14-24.

Arinez, A., Bouzidi, M., Koo, B., Sayeed, A., Serenata, C., Suarez, E., \& Sulaiman, A. B. (2002). Creating a Work Climate That Motivates Staff and Improves Performance. The Manager Journal, 11, Article No. 2002.

Armstrong, M. (2009). Armstrong's Handbook of Human Resource Management Practice (11th ed.). London and Philadelphia: KOGAN PAGE. 
Bland, J. M., \& Altman, D. G. (1997). Statistics Notes: Cronbach's Alpha. BMJ, 314, 572. https://doi.org/10.1136/bmj.314.7080.572

Bowling, A. (2014). Research Methods in Health: Investigating Health and Health Services. UK: McGraw-Hill Education.

Bullock, E. P. (2017). An Explanatory Sequential Mixed Methods Study of the School Leaders' Role in Students' Mathematics Achievement through the Lens of Complexity Theory. All Graduate Theses and Dissertations, 6096.

Chigudu, S., Jasseh, M., d'Alessandro, U., Corrah, T., Demba, A., \& Balen, J. (2014). The Role of Leadership in People-Centered Health Systems: A Sub-National Study in the Gambia. Health Policy and Planning, 33, e14-e25.

https://doi.org/10.1093/heapol/czu078

Creswell, J. W., \& Plano Clark, V. L. (2011). Designing and Conducting Mixed Methods Research (2nd ed.). Thousand Oaks, CA: Sage.

Daniel, W. (2009). Biostatistics: A Foundation for Analysis in the Health Sciences (9th ed.). New York: John Wiley and Sons Inc.

Federal Ministry of Health of Ethiopia (FMOH) (2015). Health Sector Transformation Plan. Addis Ababa: FMOH.

Federal Ministry of Health of Ethiopia (FMOH) (2016). Health and Health Related Indicators of Ethiopia for the Year 2016/2016. Addis Ababa: FMOH.

Federal Ministry of Health of Ethiopia (FMOH) (2017). Leadership, Management and Governance In-Service Training Manual for Health Managers at Hospitals and Health Centers. Addis Ababa: FMOH.

Gershon, R. R., Stone, P. W., Bakken, S., \& Larson, E. (2004). Measurement of Organizational Culture and Climate in Healthcare. The Journal of Nursing Administration, 34, 33-40. https://doi.org/10.1097/00005110-200401000-00008

Global Health Leadership Institute (2016). The Primary Health Care Management Development Program. Participant Manual, New Haven, CT and Addis Ababa, Ethiopia.

International Institute of Primary Health Care in Ethiopia (2017). Transformation Leadership. Addis Ababa: IIPHCE.

Kirkpatrick, D., \& Kirkpatrick, J. (2006). Evaluating Training Programs: The Four Levels. San Francisco: Berrett-Koehler Publishers.

Kurt, S. (2016). Kirkpatrick Model: Four Levels of Learning Evaluation. In Educational Technology.

https://educationaltechnology.net/kirkpatrick-model-four-levels-learning-evaluation/

La Rue, K. S., Alegre, J. C., Murei, L., Bragar, J., Thatte, N., Kibunga, P., \& Cheburet, S. (2012). Strengthening Management and Leadership Practices to Increase Health-Service Delivery in Kenya: An Evidence-Based Approach. Human Resources for Health, 10, 25. https://doi.org/10.1186/1478-4491-10-25

LeMay, N. V., \& Ellis, A. (2007). Evaluating Leadership Development and Organizational Performance. In K. M. Hannum, J. W. Martineau, \& C. Reinelt (Eds.), The Handbook of Leadership Development and Evaluation (pp. 228-260). San Francisco, CA: Jossey-Bass.

Likert, R. (1932). A Technique for the Measurement of Attitudes. Archives of Psychology, 140, 1-55.

Management Sciences for Health (MSH) (2005). Managers Who Lead: A Handbook for Improving Health Services. Cambridge, MA: MSH.

https://www.msh.org/resources/managers-who-lead-a-handbook-for-improving-health -services 
Menard, S. (1995). Applied Logistic Regression Analysis: Sage University Series on Quantitative Applications in the Social Sciences. Thousand Oaks, CA: Sage.

Mutale, W., Vardoy-Mutale, A. T., Kachemba, A., Mukendi, R., Clarke, K., \& Mulenga, D. (2017). Leadership and Management Training as a Catalyst to Health System Strengthening in Low-Income Settings: Evidence from Implementation of the Zambia Management and Leadership Course for District Health Managers in Zambia. PLoS ONE, 12, e0174536. https://doi.org/10.1371/journal.pone.0174536

Packard, T., \& Jones, L. (2015). An Outcomes Evaluation of a Leadership Development Initiative. Journal of Management Development, 34, 153-168. https://doi.org/10.1108/JMD-05-2013-0063

Pagano, M., \& Gauvereau, K. (2000). Principles of Biostatics (2nd ed.). Duxbury: Pacific Grove.

Rolle, I. V., Zaidi, I., Scharff, J., Jones, D., Firew, A., Enquselassie, F., Negash, A., Deyessa, N., Mitike, G., Sunderland, N., \& Nsubuga, P. (2011). Leadership in Strategic Information (LSI) Building Skilled Public Health Capacity in Ethiopia. BMC Research Notes, 4, 292. https://doi.org/10.1186/1756-0500-4-292

Rowe, A. K., Rowe, S. Y., Peters, D. H., Holloway, K. A., Chalker, J., \& Ross-Degnan, D. (2018). Effectiveness of Strategies to Improve Health-Care Provider Practices in Low-Income and Middle-Income Countries: A Systematic Review. The Lancet Global Health, 6, e1163-e1175. https://doi.org/10.1016/S2214-109X(18)30398-X

SPSS Inc. (2011). IBM SPSS Statistics Base 20. Chicago, IL: SPSS Inc.

Tejda, J. J., \& Punzalan, J. R. B. (2012). On the Misuse of Slovin's Formula. The Philippine Statistician, 61, 129-136.

Uneke, C. J., Ezeoha, A. E., Ndukwe, C. D., Oyibo, P. G., \& Onwe, F. D. (2012). Enhancing Leadership and Governance Competencies to Strengthen Health Systems in Nigeria: Assessment of Organizational Human Resources Development. Healthcare Policy = Politiques de Sante, 7, 73-84. https://doi.org/10.12927/hcpol.2013.22749

USAID Transform: Primary Health Care Project (2017b). Theory of Change in Practice 2017. Addis Ababa, Ethiopia.

USAID (United States of Agency for International Development) Transform: Primary Health Care (2017a). Cooperative Agreement. Addis Ababa: USAID Ethiopia.

Wiseman, L. M. (2011). Evaluating the Effectiveness and Efficiency of Continuous Improvement Training. Master's Thesis, Corvallis, OR: Oregon State University.

World Health Organization (WHO) (2005). Strengthening Management in Low-Income Countries. Geneva, Switzerland: WHO.

World Health Organization (WHO) (2007). Everybody's Business-Strengthening Health Systems to Improve Health Outcomes: WHO's Framework for Action.

\section{Abbreviations}

ANOVA: analysis of variance; CBHI: community-based health insurance; DMR: desired measurable result; FMOH: Federal Ministry of Health; LMG: leadership, management, and governance; SD: standard deviation; SNNP: Southern Nations and Nationalities of Peoples; SPSS: Statistical Package for Social Science; USAID: United States Agency for International Development; VIF: variance inflation factor; WHO: World Health Organization; ZHD: zonal health department. 


\section{S1 File 1: Description of Block and Segmented LMG Training} Course Curriculum, and Interventions, September, 2018

Block course: A six-day class room LMG training and six-to-nine-months-long leadership project. Organized for maternal health program champions from primary health care facilities. During the project period, the trainees receive coaching from staff of in-service training institutes every $30-45$ days.

Block approach course description.

\begin{tabular}{|c|c|}
\hline Ser no & Day/Description \\
\hline 1 & Day 1 (7 hours) \\
\hline 2 & $\begin{array}{l}\text { Registration and Welcome } \\
\text { Introductions, Workshop Expectations, Ground Rules Pre-test (120 minutes) }\end{array}$ \\
\hline 3 & Module 1: Overview and Context of the Health Systems in Ethiopia \\
\hline 3.1 & UNIT 1: Existing and emerging health care issues and trends (60 minutes) \\
\hline 3.2 & UNIT 2: Health Systems Strengthening (60 minutes) \\
\hline 3.3 & UNIT 3: Health policy, strategies, and reforms in Ethiopia (75 minutes) \\
\hline 4 & Module 2: Introduction to leadership, management, and governance \\
\hline 4.1 & UNIT 1: Concepts and practices of leading, managing, and governing (90 minutes) \\
\hline 4.2 & Closing \& daily course evaluation ( 30 minutes) \\
\hline 4.3 & Day 2 (6 hours) \\
\hline 4.4 & Recap Day 1 Session (30 minutes) \\
\hline 4.5 & UNIT 1: Concepts and practices of leading, managing, and governing (285 minutes) \\
\hline 4.6 & UNIT 2: Mobilizing communities and other stakeholders to improve health (30 minutes) \\
\hline 4.7 & Closing and daily course evaluation ( 15 minutes) \\
\hline 5 & Day 3 (6 hours) \\
\hline 5.1 & Recap Day 2 Sessions (30 minutes) \\
\hline 6 & $\begin{array}{l}\text { Module Three: Improving performance through enhanced Leadership, management, } \\
\text { and governance }\end{array}$ \\
\hline 6.1 & UNIT 1: Participatory leading and managing practices (195 minutes) \\
\hline 6.2 & UNIT 2: Moving from Vision to Action (180 minutes) \\
\hline 6.3 & Closing and daily course evaluation ( 15 minutes) \\
\hline 7 & Day 4 (6 hours) \\
\hline 7.1 & Recap Day 3 sessions (30 minutes) \\
\hline
\end{tabular}




\section{Continued}

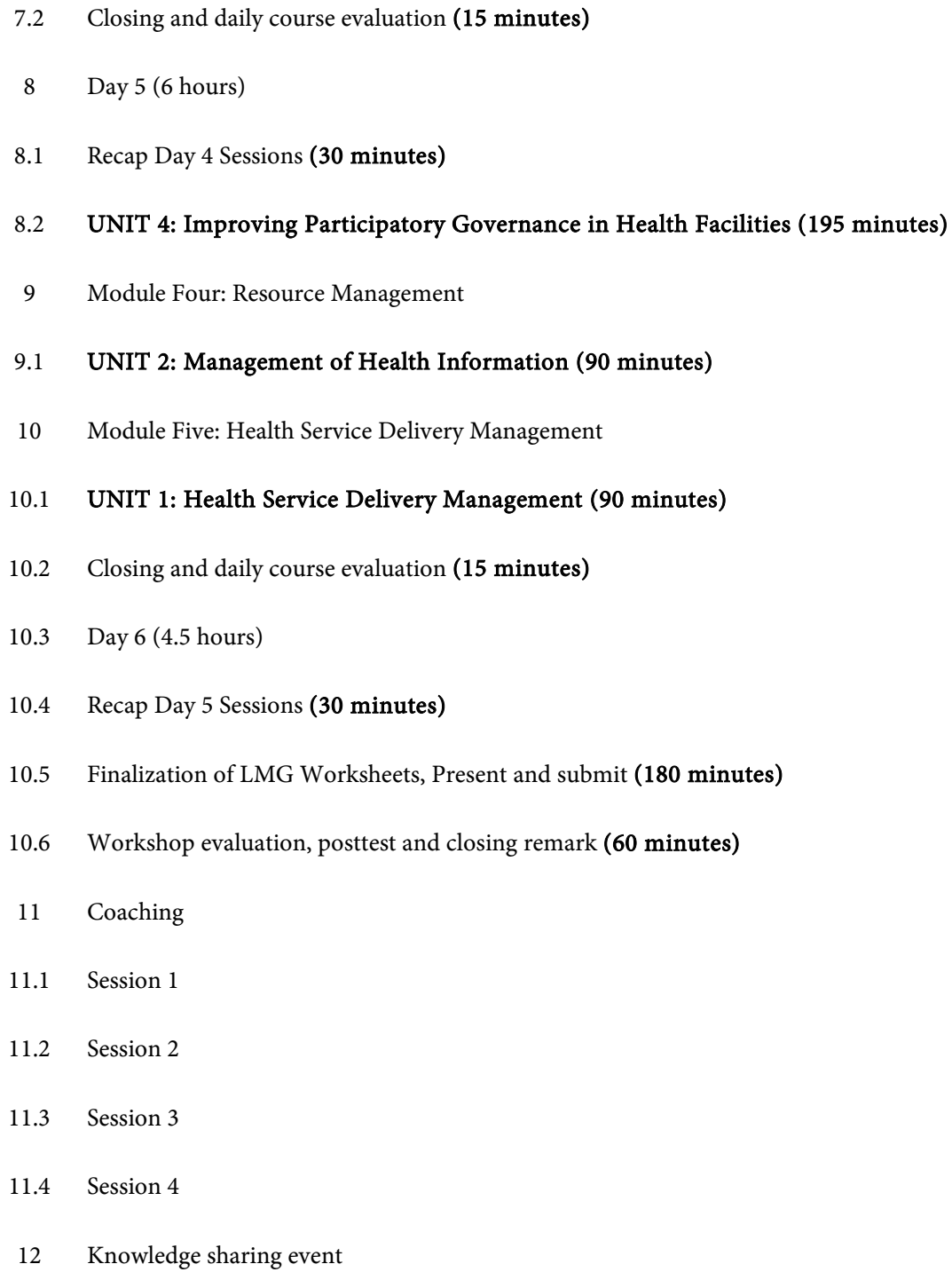

Segmented course: Two workshops of three-day classroom LMG training, and six-to-nine months-long leadership project.

Segmented I: Two or three health systems managers recruited from primary health care facilities (i.e., woreda health office, health centers, primary hospital) attend two rounds of training with a one-month gap and implement 6-month-long leadership projects. The training is held at the district level, and every 30 - 45 days, coaching is provided by zonal (regional) health departments (ZHDs).

Segmented II: Two or three health systems managers from primary health care facilities (i.e., woreda health office, health centers, primary hospital) attend two rounds of training with $1-2$ month gap and implement 6 - 9 months-long leadership projects. Every $30-45$ days, the coaching is provided by USAID Transform: PHC project field staff. 
Segmented approach course description.

\begin{tabular}{|c|c|}
\hline Ser no & Day/Description \\
\hline 1 & Workshop 1 \\
\hline 1 & Day 1 (7 hours) \\
\hline 2 & Registration and Welcome \\
\hline 2 & Introductions, Workshop Expectations, Ground Rules Pre-test (120 minutes) \\
\hline 3 & Module 1: Overview and Context of the Health Systems in Ethiopia \\
\hline 3.1 & UNIT 1: Existing and emerging health care issues and trends ( 60 minutes) \\
\hline 3.2 & UNIT 2: Health Systems Strengthening (60 minutes) \\
\hline 3.3 & UNIT 3: Health policy, strategies, and reforms in Ethiopia (75 minutes) \\
\hline 4 & Module 2: Introduction to leadership, management, and governance \\
\hline 4.1 & UNIT 1: Concepts and practices of leading, managing, and governing (90 minutes) \\
\hline 4.2 & Closing and daily course evaluation (30 minutes) \\
\hline 4.3 & Day 2 (6 hours) \\
\hline 4.4 & Recap Day 1 Session (30 minutes) \\
\hline 4.5 & UNIT 1: Concepts and practices of leading, managing, and governing (285 minutes) \\
\hline 4.6 & UNIT 2: Mobilizing communities and other stakeholders to improve health (30 minutes) \\
\hline 4.7 & Closing and daily course evaluation (15 minutes) \\
\hline 5 & Day 3 (6 hours) \\
\hline 5.1 & Recap Day 2 Sessions (30 minutes) \\
\hline 6 & $\begin{array}{l}\text { Module Three: Improving performance through enhanced Leadership, management, } \\
\text { and governance }\end{array}$ \\
\hline 6.1 & UNIT 1: Participatory leading and managing practices (195 minutes) \\
\hline 6.2 & UNIT 2: Moving from Vision to Action (180 minutes) \\
\hline \multirow[t]{4}{*}{6.3} & Closing and daily course evaluation ( 15 minutes) \\
\hline & Workshop 2 \\
\hline & Registration and Welcome \\
\hline & Introductions, Workshop Expectations, Ground Rules Pre-test (120 minutes) \\
\hline 7 & Day 1 (6 hours) \\
\hline \multirow[t]{2}{*}{7.1} & Recap Day 3 sessions (30 minutes) \\
\hline & UNIT 3: Aligning, Mobilizing and Inspiring Health Workers for Results (375 minutes) \\
\hline 7.2 & Closing and daily course evaluation (15 minutes) \\
\hline 8 & Day 2 (6 hours) \\
\hline 8.1 & Recap Day 4 Sessions (30 minutes) \\
\hline
\end{tabular}


8.2 UNIT 4: Improving Participatory Governance in Health Facilities (195 minutes)

9 Module Four: Resource Management

9.1 UNIT 2: Management of Health Information (90 minutes)

10 Module Five: Health Service Delivery Management

10.1 UNIT 1: Health Service Delivery Management (90 minutes)

10.2 Closing and daily course evaluation (15 minutes)

10.3 Day 3 (4.5 hours)

10.4 Recap Day 5 Sessions (30 minutes)

10.5 Finalization of LMG Worksheets, Present and submit (180 minutes)

10.6 Workshop evaluation, posttest and closing remark (60 minutes)

$11 \quad$ Coaching

11.1 Session 1

11.2 Session 2

11.3 Session 3

11.4 Session 4

12 Knowledge sharing event 


\section{S2 File 2: Sample Leadership Project against Results Documented in Selected Primary Health Care Facilities, September 2018}

\begin{tabular}{|c|c|c|c|}
\hline Region & Topic & Challenges/projects & $\begin{array}{c}\text { Reported results } \\
\text { (Aug } 2017 \text { - Sept 2018) }\end{array}$ \\
\hline \multirow{5}{*}{ Amhara } & $\begin{array}{l}\text { Woreda } \\
\text { standards }\end{array}$ & $\begin{array}{l}\text { June 2018: increase woreda } \\
\text { management standards met from } \\
53 \% \text { to } 75 \% \text {. (HSS project, \#21). }\end{array}$ & $\begin{array}{l}\text { Increased woreda } \\
\text { management standards } \\
\text { met from } 53 \% \text { to } 96 \% \text {. }\end{array}$ \\
\hline & $\begin{array}{c}\text { ANC4+ service } \\
\text { uptake }\end{array}$ & $\begin{array}{l}\text { June 2018: increase ANC4+ service } \\
\text { uptake coverage from } 48 \% \text { to } 75 \% \text {. } \\
\text { (Maternal and neonatal health: } \\
\text { ANC project, \#60). }\end{array}$ & $\begin{array}{c}\text { Increased ANC4+ service } \\
\text { uptake coverage from } \\
48 \% \text { to } 58 \% \text {. }\end{array}$ \\
\hline & Skilled delivery & $\begin{array}{c}\text { June 2018: increase skilled delivery } \\
\text { service uptake coverage from } 64 \% \\
\text { to } 70 \% \text {. (Maternal and neonatal } \\
\text { health: delivery project, \#7). }\end{array}$ & $\begin{array}{l}\text { Increased skilled delivery } \\
\text { service uptake coverage } \\
\text { from } 64 \% \text { to } 71 \% \text {. }\end{array}$ \\
\hline & Immunization & $\begin{array}{c}\text { Aug 2018: decrease Penta3 } \\
\text { defaulter rate from } 7 \% \text { to } 5 \% \text {. } \\
\text { (Child health-immunization, } \# 69 \text { ). }\end{array}$ & $\begin{array}{l}\text { Decreased Penta3 defaulter } \\
\text { rate from } 7 \% \text { to } 3 \% \text {. }\end{array}$ \\
\hline & $\begin{array}{l}\text { Severe acute } \\
\text { malnutrition }\end{array}$ & $\begin{array}{c}\text { Aug 2018: decrease severe acute } \\
\text { malnutrition (prevalence rate } \\
\text { from } 3.6 \% \text { to } 1 \% \text {. (Nutrition } \\
\text { project, \#75) }\end{array}$ & $\begin{array}{c}\text { Decreased severe acute } \\
\text { malnutrition prevalence rate } \\
\text { from } 3.6 \% \text { to } 1.3 \% .\end{array}$ \\
\hline \multirow{3}{*}{ Oromia } & $\begin{array}{c}\text { Disease } \\
\text { Prevention }\end{array}$ & $\begin{array}{l}\text { By end of Feb 2018, increase TB } \\
\text { case detection rate from } 40 \% \text { to } \\
60 \% \text {. (Other: TB prevention and } \\
\text { control project, \#122) }\end{array}$ & $\begin{array}{l}\text { TB case detection rate remained } \\
40 \% \text { (did not meet the desired } \\
\text { measurable result.) }\end{array}$ \\
\hline & $\begin{array}{l}\text { Community-based } \\
\text { health insurance }\end{array}$ & $\begin{array}{l}\text { By end of Oct } 2018, \text { increase } \\
\text { proportion of households } \\
\text { enrolled in CBHI scheme from } \\
8 \% \text { to } 75 \% \text {. (CBHI project, \#156) }\end{array}$ & $\begin{array}{l}\text { Increased the proportion of house- } \\
\text { holds enrolled in CBHI scheme } \\
\text { from } 8 \% \text { to } 25 \% \text {. }\end{array}$ \\
\hline & $\begin{array}{c}\text { Disease } \\
\text { prevention }\end{array}$ & $\begin{array}{l}\text { By end of July } 2018 \text {, decrease } \\
\text { the prevalence malaria positivity } \\
\text { rate from } 2.8 \% \text { to } 0.8 \% \text {. (Other: } \\
\text { malaria prevention and control } \\
\text { project, } \# 147 \text { ) }\end{array}$ & $\begin{array}{l}\text { Decreased the prevalence } \\
\text { malaria positivity from } \\
2.8 \% \text { to } 0.7 \% \text {. }\end{array}$ \\
\hline \multirow{2}{*}{ SNNP } & Family Planning & $\begin{array}{c}\text { By end of December 2017, } \\
\text { increase modern contraceptive } \\
\text { acceptance rate from } 34 \% \text { to } \\
60 \% \text {. (FP project, } \# 215 \text { ) }\end{array}$ & $\begin{array}{l}\text { Increased modern } \\
\text { contraceptive acceptance } \\
\text { rate from } 34 \% \text { to } 67 \% \text {. }\end{array}$ \\
\hline & $\begin{array}{l}\text { Community-based } \\
\text { health insurance }\end{array}$ & $\begin{array}{l}\text { By end of June } 2018 \text {, increase } \\
\text { the proportion of households } \\
\text { enrolled in CBHI scheme from } \\
15 \% \text { to } 100 \% \text {. (CBHI project, } \# 241 \text { ) }\end{array}$ & $\begin{array}{l}\text { Increased the proportion of } \\
\text { households enrolled in CBHI } \\
\text { scheme from } 15 \% \text { to } 64 \% \text {. }\end{array}$ \\
\hline Tigray & Hospital Reform & $\begin{array}{l}\text { By end of Feb 2018, increase } \\
\text { hospital services transformation } \\
\text { guidelines standards met from } \\
30 \% \text { to } 70 \% \text {. (HSS project, \#93) }\end{array}$ & $\begin{array}{c}\text { Increased hospital services } \\
\text { transformation guidelines } \\
\text { standards met from } \\
30 \% \text { to } 69 \% \text {. }\end{array}$ \\
\hline
\end{tabular}

